\title{
Emir Rodríguez Monegal y "Los dos Asturias"
}

A quienes es familiar el enfoque que da el señor Rodríguez Monegal al estudio de literatura latinoamericana de hoy, no les habrá sorprendido lo que implicaba el título de su artículo sobre Miguel A. Asturias en el número 67 de Revista Iberoamericana (enero a abril de 1969, pp. 13-20): "Los dos Asturias". Su probable actitud ante Asturias habría podido adivinarse tras un breve examen de su actitud generaî ante la llamada nueva novela latinoamericana, tan alentada por él, y de la que se excluye específicamente a Asturias. Lo que sí nos sorprendió fue la inconsistencia de la valoración que hace el señor Rodríguez Monegal de la obra de Asturias, y su evidente renuncia a emprender una verdadera investigación de las novelas del autor citado. Al analizar atentamente su tesis nos vemos obligados a formular una conclusión bastante asombrosa: que el campeón de la nueva novela latinoamericana no ha logrado comprender la obra del que en 1967 fue nombrado Premio Nobel de Literatura, y a quien considera representante de la "vieja" novela por pertenecer a una generación anterior.

Aparte de las implicaciones muy problemáticas de pegarles etiquetas generalizadas a autores y movimientos literarios, declarando que "empiezan acá y terminan allá", es posible poner en duda hasta la lógica más básica de la tesis del señor Rodríguez Monegal. No podemos aceptar que la "edad de oro" (o como quiera que se la llame) de Asturias se limite a la década 1946-56, como tampoco aceptamos la versión tan incompleta que se nos presenta de su aportación a la literatura latinoamericana del siglo $\mathrm{xx}$. Y rechazamos por completo todo "análisis crítico" que en cuatro palabras busca menospreciar novelas que por su complejidad siguen confundiendo a la crítica y al público en general. La historia es vieja: el crítico se atiene a una concepción dada de la literatura que le interesa, y por motivos personales o profesionales se empeña en mantenerla, cualesquiera sean las razones que surjan en su contra. 
Así es que el señor Rodríguez Monegal afirma que la década decisiva de Asturias comienza en 1946, año en que se publica El Señor Presidente, y termina en 1956, después de la publicación de Hombres de maiz, Viento fuerte, El papa verde y Weekend en Guatemala. Pasa por alto las Leyendas de Guatemala (1930), porque "lo mejor de las Leyendas resultará incorporado a libros posteriores", con lo que volvemos al compartimiento de contenidos e influencias literarias como si fútan entidades con peso y medida. Ahora bien, es de suponer que cuando el señor Rodríguez Monegal se refiere a los logros literarios de Miguel Angel Asturias en esa década, nos está hablando de sus logros artísticos, ya que el verdadero reconocimiento crítico de ellos no le fue conferido a Asturias sino hasta mucho más tarde, y siendo así, tenemos que subrayar de nuevo nuestra inconformidad. Cuando el señor Rodríguez Monegal acepta, precisamente en el artículo que nos ocupa, que El Señor Presidente ya estaba escrito en forma definitiva en 1932, ¿qué sentido tiene referirse a la década 1946-56 como la de la verdadera actividad creadora?

En lo que toca a la historia de la literatura latinoamericana, no cabe duda de que El Señor Presidente pertenece a 1946; pero si se trata de discutir la coherencia creadora de un autor individual, que es lo que le interesa principalmente al señor Rodríguez Monegal, según parece, es forzoso colocar esta novela no en el período de los años 40 , sino en el de los 20, cuando se escribió, y vista así sería contemporánea a las Leyendas. El señor Rodríguez Monegal no nos aclara los principios que forman su punto de partida. No distingue en la forma debida entre los criterios con los que se enjuicia a un escritor como creador individual, $y^{\prime}$ los principios, muy distintos por supuesto, con los cuales se le ha de juzgar como fenómeno o fuente de influencias dentro de la literatura de su época.

Sin embargo, todavía falta la afirmación más discutible, que es la siguiente: "Otorgado en 1949, cuando Asturias había publicado sus tres libros más importantes [el Premio], habría sido unánimemente aplaudido." Esta nos parece una declaración muy sorprendente, por no decir absurda. En 1949 apenas si se conocía a Asturias en América, y en el resto del globo ni hablar. De sus libros publicados, sólo uno, Leyendas de Guatemala, se había traducido, y eso en 1930, al francés. Nos interesaría ver la evidencia que le induce al señor Rodríguez Monegal a hacer esta afirmación extraordinaria. ¿Dónde se publicaron los estudios críticos y en serio de El Señor Presidente y de Hombres de maiz que pudieran formar la base para apoyar a Asturias como candidato al Premio Nobel? No existen. $Y$ casi todos los críticos saben perfectamente que aun ahora contamos con muy pocos. En 1951, J. Loveluck se vio movido a lamentai 
que El Señor Presidente hubiera pasado "como una novela más". " Hombres de maiz, que se publicó precisamente en el año en que, según se nos afirma, a Asturias debió adjudicarse el Premio, ha recibido una que otra reseña superficial, y nada más hasta el presente.

Afortunadamente, estos hechos no hay que aceptarlos a fe nuestra, pues pueden corroborarse muy fácilmente con sólo examinar la excelente bibliografía del señor Pedro F. de Andrea, que aparece en el mismo número de la Revista Iberoamericana que publicó el ensayo del señor Rodríguez Monegal. Sin embargo, hay otra objeción más obvia a la tesis que nos ocupa, y que se les habrá ocurrido ya a quienes hayan leído lo anterior. El reconocimiento que proporciona el Premio Nobel —no nos interesa aquí su validez o carencia de ella- viene casi siempre después de largos años en que un escritor ha ido acumulando una obra de más o menos "evidente" valor, y con la suficiente anterioridad al año de que se trata para que se la pueda juzgar desde una adecuada perspectiva crítica. En 1949 Asturias no era célebre, y no era mucho lo que había publicado; y claro es que la Academia Sueca habría tenido que actuar muy de prisa para otorgarle el Premio a Asturias a base de Hombres de maíz, publicada ese mismo año, y que el señor Rodríguez Monegal considera lo mejor de Asturias. Pero ahora entramos en lo absurdo: únicamcnte añadimos que si es "anacronismo" otorgarle el Premio a Asturias en 1967, entonces todo juicio crítico o histórico es irremediablemente anacrónico, y nos deberíamos guiar por la improvisación periodística en estos asuntos.

Hasta aquí hemos procedido como si aceptáramos la tesis fundamental que nos presenta el señor Rodríguez Monegal, de un Asturias anticuado y fuera de moda; nos hemos limitado a indicar que aunque esta tesis fuera aceptable, no por eso setía lógico negarle el Premio a Asturias en 1967. (Después de todo, si Asturias era tan célebre y tan meritorio en 1949, es de suponer que él, más que nadie, era una enorme influcncia, de lectura obligada, para los jóvenes que ahora escriben la nueva novela.) Sin embargo, no consideramos que la tesis fundamental sea aceptable. $\mathrm{Si}$ existen dos Asturias, forman parte de un solo hombre, y la disyuntiva no puede establecerse cronológicamente, sino que se percibe en mayor o menor grado en cada obra suya. La Academia Sueca subrayó no sólo la solidaridad del autor con su pueblo en la lucha que acometió contra la

1 Juan Loveluck , "Sobre una novela de nuestro tiempo", Atenea, núm. 310 (Concepción, abril de 1951), pp. 49-63. Loveluck escribió: "Es lástima que esta obra maciza, de verdadero espíritu americano, no haya impresionado más fuertemente a la crítica. Ha pasado casi como una novela más. Los comentarios han sido superficiales, comentarios galantes..." (p. 63). 
United Fruit, sino también su profunda comprensión de las tradiciones y leyendas de su país como fuerzas vivas, $\mathrm{y}$ fue éste el aspecto que de hecho citaron en el veredicto final.

No nos apoyamos únicamente en el fallo de la Academia Succa. Es de suponer, ya que no lo menciona, que el señor Rodríguez Monegal no había leído el excelente artículo de Guillermo Yepes-Boscán, "Asturias, un pretexto del mito", en el que se afirma que las dos temáticas sobresalientes de la obra asturiana (mito y protesta política), son precisamente lo que hace que Asturias sea el escritor más representativo de la América Latina en este siglo. ${ }^{2}$ El artículo de Yepes-Boscán es sin duda el que ofrece la interpretación más densa y coherente del significado de Asturias como fenómeno literario. Por una exquisita ironía, su tesis se basa en una idea semejante a la propuesta por Carlos Fuentes precisamente en una entrevista con Rodríguez Monegal. ${ }^{3}$ En esta concepción Asturias es el escritor que con más claridad ha percibido la función tanto del lenguaje como del mito en la novela, y de todos es sabido que éstas son las características que más indiscutiblemente definen la nueva novela. YepesBoscán recoge la concepción que repetidas veces Asturias ha expuesto de si mismo, como el Gran Lengua, o medio expresivo, de su pueblo. A partir de esta idea, Yepes-Boscán sugiere que la obra đe Asturias representa un esfuerzo por crear y poblar su propio cosmos literario, como paralelo personal a la cosmogonia mítica que descubrimos en el Popol Vub y otros libros sagrados de los mayas. Yepes-Boscán demuestra que lo folletinesco de la trilogía bananera es io menos instintivo y natural de la obra de Asturias, aun cuando en la misma trilogía sigue imperando la fuerza creadora del mito. Su artículo aprovecha el pensamiento de I.évi-Strauss y Eliade para dar, por primera vez, cierta base lógica y coherente a las afirmaciones tan a menudo emotivas e imprecisas publicadas por Asturias en revistas y diarios.

2 Guillermo Yepes-Boscán, "Asturias, un pretexto del mito", Aportes. núm. 8 (París, abril de 1968), pp. 99-116.

3 De hecho, la tesis de Yepes-Boscán sintetiza los puntos de vista sostenidos por Carlos Fuentes y Fernando Alegría al respecto. Fuentes, entrevistado por Rodríguez Monegal ("Situación del escritor en Ámérica Latina", Mundo Nuevo, París, julio de 1966, pp. 5-21), señala a Asturias y a Borges como los dos grandes innovadores, tesis plenamente aceptada por Rodríguez Monegal en aquella ocasión. Asimismo, en Novelistas contemporáneos bispanoamericanos (Heath and $\mathrm{Co}$., Boston 1964), Alegría hace el comentario siguiente: "Miguel Angel Asturias en Hambres de maiz (1949) y Alejo Carpentier en El reino de este mundo (1949) y Los pasos perdidos (1953)... dieron categoría estética y significación social a la mitología del Caribe y de Centro América, adelantándose así y asumiendo un papel precursor que los escritotes de las nuevas generaciones les reconocen sin discusión" (p, 4). 
Es aquí donde llegamos a un problema central. En el fondo, Asturias no es un artista consciente, y sería muy importante considerar el efecto de su herencia maya en este sentido. Es capaz de decir una cosa cuando quiere decir otra, o de adoptar una actitud dada y creer muy sinceramente que ha adoptado otra diferente: sus opiniones políticas, por ejemplo, son puramente humanísticas y no ideológicas. En una época en la que los escritores americanos más jóvenes disfrutan de un ambiente intelectual que les permite comportarse casi como estrellas de cine, Asturias está "fuera de onda". Ya se alejó un poco de la etapa bohemia, en la que se pasa el tiempo en el quartier latin de la literatura. No siente la necesidad de estar "in" en sus declaraciones, y de hecho nunca presumió de grandes dones de intelecto, ni hizo alarde de su celebridad. La verdad, difícil de aceptar en estos tiempos, es que no es intelectual, sino poeta, y poeta a la antigua, es decir, de los que no saben qué van a decir hasta después de que lo han dicho. La psicología moderna -Jung, en especial- y otras teorias recientes, nos enseñan que esto no actúa necesariamente contra la creación de obras dotadas de unidad artística. Al examinar las declaraciones críticas hechas por Asturias respecto a sus propios libros a través de los últimos veinte años, nos hallamos frente a una suma de opiniones que no se distinguen en nada por su invención y originalidad. La explicación es muy sencilla, y es que el mismo Asturias está tratando de encontrar razones y explicaciones a su propia obra, cosa que no hace nunca en el acto de escribirla. En el fondo Asturias no comprende verdaderamente su propia obra, si "comprender" abarca la capacidad de explicar lo que "significa"; y sin embargo, él la escribió, y tiene su lógica interna. Es por esto por lo que tan repetidas veces afirma que hasta esa obra tan apolítica que es Mulata de tal constituye una novela de protesta y que cada novela escrita por él ha de considerarse un "testimonio".

Si ha de elucidarse alguna vez el significado más profundo de la obra asturiana, los críticos tendrán que cambiar de actitud, para ir al rescate de este escritor tan humilde; si no, él nos convencerá, y todas esas aventuras creadoras que son sus novelas se verán convertidas en literatura de protesta, etiqueta que sólo puede aplicarse a la trilogía y a Weekend en Guatemaia. En vez de incurrir en el diletantismo que recientemente han promovido fenómenos tales como las entrevistas en Mundo Nuevo, Asturias, aun después de otorgársele el Premio Nobel, sigue tratando las entrevistas como una oportunidad para charlar, y se empeña en insistir en que, por un lado, su obra no es más que la voz de Guatemala que se expresa por él, y por otro lado, en que recibió el Premio en nombre de la América Latina entera. 
Si el señor Rodríguez Monegal se hubiera salido con la suya, a Asturias se le habría negado incluso estos humildes placeres, pues comenta: "a medida que Asturias iba publicando los volúmenes de su novela-rio [la trilogía], el divorcio entre su óptica y la đe los mejores escritores latinoamericanos de hoy se hacía más evidente". Asturias, por lo visto, no sólo no es representativo, sino que ni sıquiera figura entre los "mejores escritores latinoamericanos de hoy". Este "homenaje" (pues fue en el número de Revisła Iberoamericana que se dedicó a Miguel Angel Asturias donde apareció el ensayo de Rodríguez Monegal) no es tal homer naje. Su lógica nos parece la del iceberg, y tenemos que considerar la posibilidad de que el señor Rodríguez Monegal no estaba dispuesto a escribir todo lo que motivó su artículo. Desgraciadamente, no llegamos todavía a lo peor. Al esforzarse en demostrar, cueste lo que cueste, que Asturias no debió ganar un premio literario, recurre a la discusión de cuestiones políticas. En concreto pone en duda la probidad política del escritor, insinuando que a la vez que llevaba a cabo su denuncia novejesca del imperialismo económico estadounidense, Asturias estaba modificando sus actitudes politicas por razones oportunistas. ${ }^{4}$ Aunque fuera verdad, este detalle no vendría al caso y le da muy poco crédito al señor Rodríguez Monegal. Da una conclusión poco elevada a un artículo que en ningún momento se distingue por su enfoque crítico, por lo menos en el sentido literario. No es la única, ni tampoco la más mezquina de las reacciones adversas que han surgido frente al alto honor con que se ha premiado a Asturias; pero sí es la más eminente. Es necesario observar que el problema, según los términos en que lo plantea el señor Rodríguez Monegal, es una cuestión puramente literaria, que debería discu-

4 No podemos precisar la opinión del señor Rodríguez Monegal respecto a esta cuestión política. El se limita a declarar malintencionadamente que Asturias ya empezó a aliarse con "grupos que él había combatido", y que "la izquierda latinoamericana no ha perdonado a Asturias esta actitud, especialmente en momentos en que nuevos brotes de guerrilla asolaban su patria." Naturalmente el señor Rodríguez Monegal no aclara su propia situación: ¿Es él de la izquierda latinoamericana? ¿Qué relación existe entre la nueva novela y el izquierdismo? ¿La guerrilla es siempre digna de alabarse? ¿ ¿Da él su apoyo a los guerrilleros que están luchando en Guatemala? El señor Rodríguez Monegal sólo nos comunica lo que han dicho los demás. En esta situación lo más honrado es que nosotros diga. mos nuestra propia opinión. En 1966 nadie sabía cuál sería la postura del nuevo gobierno, sobre todo después de la muerte del que había de ser presidente. En una situación en que los guerrilleros ya estaban en el pais antes de iniciarse la obra del nuevo régimen, que todos creían democrático en aquel entonces, es muy difícil saber a ciencia cierta qué es lo que ha pasado en Guatemala durante los últimos tres años. Una cosa sí es cierta: si Asturias hubiera renunciado a su cargo diplomático después de recibir el Premio Nobel, lo que seguramente debía ser una gran tentación, entonces sí se le podría haber tachado de oportunista. Pero no lo hizo. 
tirse en términos literarios, y no otros. Sin embargo, después de condenar, él mismo, el tenor excesivamente político de algunas obras de Asturias, se. pone a enjuiciar su valor literario a la luz de cuestiones políticas que le son enteramente externas.

Volvamos, pues, a la literatura. Quizá el aspecto más deprimente de todo este triste asunto sea que el señor Rodríguez Monegal se niegue tan rotundamente - sin confesarlo- a profundizar en las novelas de Asturias. Lo poco que hace en este sentido se ve lleno de inconsistencias, o de ideas que pierden toda su fuerza cuando se las coloca dentro del contexto más profundo de la obra a la que se refieren. ¿Qué hemos de pensar de declaraciones tan extraordinarias como la que sigue: que en la obra de Asturias "los indígenas son presentados como seres paszvos que casi nunca tienen éxito en su rebelión"? (subrayado nuestro). No es cuestión de ocuparnos de pequeñeces, sino de ejemplificar uno de los casos más sucintos de los argumentos mal pensados que siempre resultan de nociones preconcebidas, y cuyo único propósito es el de salvaguardar esas nociones a todo precio.

El Señor Presidente es una novela que algunos puedan considerar única, y no sólo en el ámbito americano sino en el de todo el mundo, cuya estructura interna no ha sido lo suficientemente dilucidada; ${ }^{5}$ no obstante, ahora sucede que sufre de "importantes debilidades de estructura". La estructura, según nos aclara el señor Rodríguez Monegal, es la creación de un estilo homogéneo que se sostiene de principio a fin en una novela: "el poder descriptivo, la felicidad del lenguaje, el sistema de brillantes metáforas, no se sostiene de la primera a la última página. "Es evidente que el señor Rodríguez Monegal ha descubierto un nuevo concepto de la estructura literaria (¿no podría ser, acaso, algo aproximadamente equivalente a aquellos viejos conceptos nuestros, ya tan fuera de moda, "estilo" y "tono"?), pero no nos revéla su secreto y al parecer ño siente la necesidad de proporcionarnos ejemplos textuales para confirmar sus afirmaciones.

Pero tales ejemplos son necesarios. Sin ellos, no vamos a creer que "Capitulos esperpénticos como los iniciales son reemplazados por páginas y páginas de narración realista". Una breve ojeada a cualquier artículo periodístico escrito por Asturias, lo mismo que una breve conversación con él, 'son generalmente suficientes para convencer al observador menos interesado de que Asturias no es capaz de escribir nada en forma "realis-

5 Véase sin embargo la excelente tesis doctoral de Carlos Navarro, "The Destruction of Reality in El Señor Presidente", University of Pittsburgh, 1967. 
ta". La visión que nos ofrece Yepes-Boscán del "realismo" asturiano es más profunda: es "el lenguaje, la realidad primera, el único realismo que el escritor auténtico conoce". ${ }^{6}$ Siendo un escritor instintivo, el estilo de Asturias nunca varía dentro de las demandas temáticas de cada novela. No obstante, el señor Rodríguez Monegal concluye que El Señor Presidente es un "híbrido", una combinación mal concebida y mal compuesta de dos estilos mutuamente incompatibles. Aquí nos revela que ha conseguido sentir de manera intuitiva una parte del secreto de esta novela, para después rechazarla por no poder ir más lejos.

Ya que ésta es la única novela que el señor Rodríguez Monegal trata siquiera en forma superficial, vamos a of recer una breve síntesis de la concepción que de ella tenemos nosotros, aunque nuestro verdadero propósito es únicamente el de demostrar lá no vigencia de la tesis más general que ha dado a conocer. Para nosotros esta novela es un sistema de polaridades, como son lo bueno y lo malo, la luz y la sombra, lo cons. ciente y lo inconsciente, lo bello y lo feo, la vida y la muerte, etc., antitesis que se reconcilian mediante una serie muy compleja de correlaciones poéticas. El señor Rodríguez Monegal llama "escritura híbrida" a la construcción de un complejo poema en prosa, desarrollado a muchos niveles ético-estéticos, y que desemboca en un dualismo central a base del contraste típicamente asturiana entre lo real y lo irreal. Es precisamente aquí donde reside el arte de la novela. En El Señor Presidente se nos presenta una alternación constante entre la visión emotiva y la racional de su situación central, y así se consigue reproducir el divorcio entre percepción y comprensión en la psique moderna, y lo que es más importante, unificarlas mediante su arte, el arte de su lenguaje.

Gran parte de la tesis del señor Rodríguez Monegal respecto a esta novela se apoya en lo que él considera la mal concebida trayectoria moral de su protagonista, Cara de Angel; pero una vez más parte de una petición de principio, y de nuevo el resultado es la deformación en el enfoque. No hay en el libro la menor prueba de que Cara de Angel quede redimido por el amor, aunque sí llega a un momento que podría llamarse individuación, en la terminología de Jung. Al contrario, lejos de dar una "vuelta completa" y de estar "dispuesto a enfrentarse al dictador", el mismo Cara de Angel lamenta su continuada cobardía y servilismo, y es detenido precisamente cuando huye a Washington para escaparse del tirano. Si emprendiéramos un escrutinio de los antecedentes de su noviazgo con Camila, y su examen psicológico de lo que motiva las pocas acciones

6 Yejes-Boscán, p. 101. 
buenas que a última hora comete, el resultado sería otro muy distinto del que nos presenta el señor Rodríguez Monegal. No obstante, él afirma que Cara de Angel es redimido, y según su criterio, esto hace que la novela se convierta en melodrama; pero la novela es melodrama desde la primera página, y este aspecto es algo que tenemos que aceptar antes de empezar a discutirla de veras. También es muchas cosas más, y la forma en que Asturias consigue moldearlas y unirlas es lo que verdaderamente nos interesa.

La trama y los personajes tienen un papel poco común en las novelas de Asturias, sobre todo en El Señor Presidente y Hombres de maíz. Cara de Angel y sus acciones tienen una función formal específica por encima del significado ético-psicológico que normalmente establece el movimiento de la trama; Cara de Angel viene a ser el motivo central de un como mosaico, uniendo así los aspectos morales y estéticos como raras veces lo ha conseguido autor alguno, y menos en una novela que se dice "política". Dada la ausencia de un verdadero substrato mítico, el mismo Presidente se vuelve leyenda, y el inconsciente colectivo de cada cual viene a ser el "pasado" en que reside, mientras que Cara de Angel se nos aparece como el medio consciente en que toman su forma más precisa las diversas corrientes de la novela.

Mientras el señor Rodríguez Monegal se niegue a proporcionar ejemplos para corroborar sus afirmaciones - y conste que si El Señor Presidente no se trata tanto en forma de poema como de novela, se pierde lo más importante - no será posible decir más acerca de lo que ha opinado sobre esta novela, $\mathfrak{u}$ otra novela cualquiera. Desgraciadamente, el ensayo que discutimos aquí, al igual que tantos otros estudios suyos, se compone enteramente de conclusiones y carece del análisis ilustrado que las verifique. Vamos a citar como ejemplo la "prueba" que nos of rece de la inferioridad de Mulata de tal frente a Hombres de maíz: "En vez de consistir, como Hombres de maíz, en una serie independiente de relatos, vinculados por la misma situación básica y por el préstamo de personajes, Mulata de $t a l$ se convierte en una serie infinita, y a la postre tediosa, de variaciones sobre motivos indígenas". Y con esto, al parecer, ya se ha dicho lo suficiente. La verdad es que la tesis del señor Rodríguez Monegal carece por completo de fundamento lógico, y no se apoya en análisis alguno del texto. No hay referencia alguna a la técnica lingǘstica tan original de esa extraña novela que es Mulata de tal, y tenemos que concluir que los miles de lectores que en 1966 (antes del Premio Nobel) hicieron que fuese la novela extranjera de mayor venta en Francia participaron en una extraordinaria aberración colectiva. 
Si aceptamos, como acepta el mismo Rodríguez Monegal, que 1932 fue el año en que se puso fin a El Señor Presidente, y si aceptamos además que Mulata de tal sea una novela válida y original, la visión que se nos ofrece de la función creadora de Miguel Angel Asturias es mucho más amplia que la of recida por el señor Rodríguez Monegal:

\section{El Señor Presidente \\ 1949 Hombres de maiz \\ 1963 Mulata de tal}

Evidentemente la tesis del señor Rodríguez Monegal, que buscaba excluir a Asturias del club de los contemporáneos, le obligaba a rechazar Mulata de tal. Y como hemos visto, la rechaza de manera muy precipitada y sumamente superficial. No tendría sentido of recer nuestra propia interpretación de este libro aquí, y este crítico no nos indica ningún camino a seguir: lo menciona únicamente para negarlo. Baste decir que ningún crítico tiene derecho a anular en cuatro palabras una novela que otros ni siquiera han empezado a examinar. En todo caso, y como ya queda dicho, el análisis del señor Rodríguez Monegal es de una incongruen. cia transparente. Para comprobar su tesis de que el significado de Asturias se limita a la década 1946-56, empieza por excluir a las Leyendas, como ya hemos notado, porque según él sus mejores aspectos habian de incorporarse a libros posteriores; no obstante, un poco más tarde nos asegura que Asturias debió ganar el Premio en 1949, porque sus tres libros más importantes - -El Señor Presidente, Hombres de maiz y las mismas Leyendas - ya estaban escritas. Todo esto nos hace sospechar de su juicio.

Puede objetarse que en las pocas páginas de que disponía el señor Rodríguez Monegal, no era posible hacer más de lo que hizo, y en esto quedamos de acuerdo: no debió intentarlo. No es posible hacer generalizaciones ligeras a base de las novelas de Asturias. No es fácil comprender las técnicas que utiliza, ni describirlas. Entre los críticos de la literatura latinoamericana (con la excepción, tal vez, de los de la Academia Sueca) no existe ningún acuerdo sobre el significado de la obra de Asturias, como tampoco de su valor, y no es posible que lo haya mientras se muestren tan poco dispuestos a examinar sus novelas de cerca. La critica ha quedado siempre muy rezagada en relación con la literatura en las culturas hispánicas, y es bastante deprimente comprobar que, después de todo, el máximo exponente de la "nueva novela" está continuando el fenómeno, sobre todo cuando sabemos perfectamente que no es por falta de capacidad crítica. 
Es difícil evitar la triste impresión de que por lo menos una parte de la motivación de esta tesis tan negativa que nos of rece el señor Rodríguez Monegal queda fuera del campo de la crítica literaria como tal. Asturias es un escritor que nunca le ha interesado profesionalmente, y sin embargo es Asturias quien llegó a ser el primer novelista latinoamericano ganador del Premio Nobel. Por lo tanto, se puede considerar que en cierto sentido es Asturias quien ha consagrado definitivamente el "boom" literario al que el señor Rodríguez Monegal alude con tanta frecuencia; pero Asturias no figura entre los nuevos novelistas, porque si así fuera esta flamante novela latinoamericana no podría llamarse nueva y lo único nuevo sería su reconocimiento mundial. La reacción del señor Rodríguez Monegal ante esta situación tan molesta para él fue la de negar la vigencia de la obra de Asturias frente al movimiento nuevo, y de proyectarla atrás, hacia los años 40, como un lejano precursor. El porqué de esta concepción parece evidente: el precursor inmediato no ha de ser Asturias, un escritor, sino un crítico, ni más ni menos que el mismo Rodriguez Monegal. Si consigue truncar la importancia de Asturias (y de otros escritores) en un momento dado -1956 - podrá seguir contemplando el panorama de la literatura latinoamericana como si fuera una especie de evolución autónoma, semejante a América antes de llegar Colón, y cuyo descubridor fue él mismó.

El señor Rodríguez Monegal se compromete a presentar su visión de Miguel Angel Asturias en "correctos términos literarios", y no cumple con este compromiso. Concluye afirmando que su tesis ha sido "abundantemente demostrada", pero lo único que queda abundantemente demostrado es que se había renunciado anteriormente a emprender un acercamiento con verdadero espíritu crítico. La historia lo había forzado por fin a considerar a Asturias, y su reacción nos demuestra cuán frágil es la presentación que nos hace de la nueva novela.

No hay nueva novela que no parta de una u otra manera de la novela anterior, y esta nueva novela latinoamericana de la que los escritores y su público se muestran tan justamente orgullosos, ha evolucionado en forma muy natural a través de los largos años en que se escribía la vieja novela. Uno de sus precursores fue Miguel Angel Asturias, pero es importante darnos cuenta de que también fue precursor de sí mismo, ya que sigue escribiendo y sigue aprovechando la experiencia sacada de sus obras anteriores. Asturias forma uno de los puentes más significativos entre la vieja y la nueva novela, pues gran parte de su función innovadora fue la aportación mítica y lingüística que él, más que nadie, introdujo en la literatura latinoamericana 
del siglo Xx. Si el señor Rodríguez Monegal se tomara la molestia de examinar más detenidamente Mulata del tal se daría cuenta de que la obra asturiana sigue desarrollándose, sobre todo en el campo del lenguaje. Decir que lo que hace Asturias en esta novela ya lo había hecho antes equivale a afirmar que la literatura es cuestión sobre todo de contenido: pero con esto volveríamos a los viejos y tan negativos enfoques que presentaban a El Señor Presidente como "novela política" y a Hombres de maiz como "novela de la tierra", y que creían que con eso ya habían hecho lo suficiente. El señor Rodríguez Monegal, por razones que ya hemos sugerido, ha querido empezar por la conclusión, y pegarle a Asturias ciertas etiquetas definitivas sin haber llevado a cabo la larga serie de estudios que todavía faltan; pero la crítica literaria, aun la que se dedica al estudio de una "nueva" novela, tiene que conformarse con la recopilación de ejemplos textuales y análisis parciales antes de llegar a sus conclusiones.

El señor Rodríguez Monegal intenta convencernos de que esta tesis suya pueda servir de piedra angular para la futura crítica de la obra asturiana; sin embargo, no aceptamos que se le estudie a Asturias a posteriori, desde el punto de vista de ciertas ideas fijas y tardías, sino que insistimos en que antes sea estudiado como individuo, como escritor original e influyente, porque todavía no hemos empezado a definirlo de veras. Solamente después de dilucidar tanto la técnica como el significado de su obra podremos ensayar una definición más duradera. Aun así, creemos haber demostrado abundantemente que hay por lo menos una visión que no sirve, y es la que nos of rece el señor Rodríguez Monegal. Asturias sigue desarrollando su círculo creador, aun cuando tiene 70 años, y nos dice que todavía no hemos visto la novela que será su Salammbô; pero de aceptar la tesis del señor Rodríguez Monegal no vale la pena de esperarla y leerla, pues pertenece ya a un pasado lejano. A fin de cuentas, lo único que hemos querido decir es que en una época en que se les conceden tantas cosas a los jóvenes, resulta un poco triste el comprobar que le digan a un anciano que ya no sirve; pero cuando no es verdad lo que le achacan, cuando él todavía tiene cosas que decir, o sea, cuando todavía representa aspectos valederos del ambiente en que radica, es algo que no podemos aceptar. Resulta algo muy parecido al prejuicio y a la injusticia; y lo que es peor, a la ingratitud.

Universidad de

Gerald Martin

Edimburgo 